\author{
Marzena Guz \\ Uniwersytet Warmińsko-Mazurski \\ Katedra Filologii Germańskiej
}

\title{
Zu den litauischen Lehnwörtern in ausgewählten Wörterbüchern der polnischen Sprache
}

S ch lü s s e lw or te: Etymologie, Lituanismen, polnische Sprache bei Wilna, Dialekte im Grenzgebiet

Überprüfen wir einschlägige Wörterbücher zum Polnischen nach litauischen Lehnwörter und beginnen wir die Suche in Stownik wyrazów obcych („Fremdwörterbuch”). Dort stellen wir elf Wörter mit angeblicher litauischer Herkunft fest. Bei vier Wörtern wird diese Herkunft schon jedoch von F. Sławski und A. Brückner widerlegt: kołduny (Sławski 1958-1965), lalka (Sławski 1970-1974), sterta, wajdelota (Brückner 1927). Die anderen Lexeme: dajna, kunigas, rauda, rojsty, szaulis, tekszla und wiata sind in den Nachschlagewerken von F. Sławski und A. Brückner nicht registriert. Auf Grund der Unzulänglichkeiten, die das Słownik wyrazów obcych aufweist, wird es aus unseren weiteren Untersuchungen ausgeschlossen. Ähnlich ist es mit dem Nachschlagewerk Etymologiczny słownik języka polskiego („Etymologisches Wörterbuch der polnischen Sprache”) von A. Bańkowski (2000). Aufschlussreich ist ein Blick in andere, relativ neue Wörterbücher: Stownik etymologiczny języka polskiego („Etymologisches Wörterbuch der polnischen Sprache”) von K. Długosz-Kurczabowa (2005) und Etymologiczny słownik języka polskiego („Etymologisches Wörterbuch der polnischen Sprache”) von W. Boryś (2005) in Bezug auf die Anwesenheit der litauischer Lehnwörter untersucht. 
Bei K. Długosz-Kurczabowa treten keine Lituanismen auf, im Nachlagewerk von W. Boryś wurden drei Lituanismen gefunden.

Die Schlussfolgerung unserer ersten Sichtung ist, dass Lituanismen in den von uns ausgewählten Wörterbüchern der polnischen Sprache sehr selten auftreten. Ziel dieses Beitrags ist, auf die Frage zu antworten, was den Grund für das Fehlen litauischer Lehnwörter in polnischen Wörterbüchern bildet.

Im Folgenden werden die Lituanismen bei W. Boryś (2005) samt ihren Bedeutungen aufgeführt:

- kulsza-S. 273, seit dem 16.Jh. 'Hüftbein', dialektal östlich auch 'Schenkel'. Eine Entlehnung aus dem lit. kùlše 'oberer Teil des Schenkels; die Hüfte'. Gegenwärtig im Gebrauch nur das abgeleitete Adjektiv kulszowy in der medizinischen Terminologie, z.B. rwa kulszowa (Hüftbeinweh n.) 'Ischias'.

- pakuty - S. 408 Pl., seit dem 18. Jh. 'kurze Flachs- oder Hanffasern, von den langen durch Kämmen und Schwingen abgetrennt [...]'. Eine Entlehnung aus dem lit. pãkulos Pl. 'Hanfwerg n.'.

- $\quad \dot{z}$ wir-S. 758, seit dem 18.Jh. 'Kies m., Schotter m.'. Eine Entlehnung aus dem lit. žvyras 'Kiessand m.'.

Unser Ergebnis bestätigt nur die bisher von der Fachwelt vertretene Meinung zur Geschichte der polnischen Sprache und zum Problem ihrer Entlehnungen. S. Słoński (1953: 139ff.) nennt deutsche, böhmische, lateinische, ukrainische, italienische und französische Einflüsse auf die polnische Sprache, litauische finden bei ihm keine Erwähnung. Z. Klemensiewicz (1965: 142ff.) ist der Ansicht, dass in der Zeitspanne vom Anfang des 16. Jahrhunderts bis zu den 80-er Jahren des 18. Jahrhunderts das Polnische folgende Sprachen beeinflussten: Böhmisch, Latein, Deutsch, Italienisch, Französisch, Russisch, Türkisch und Ungarisch. Litauisch fehlt auch hier. Seit den 80-er Jahren des 18. Jahrhunderts bis zum Jahre 1939 waren nach Z. Klemensiewicz (1972: 165ff.) folgende Lehnwörter im Polnischen erwähnenswert: lateinische, französische, deutsche, russische und englische. Auch Brückner 1927 (in M. Karaś 1974) führt keine Lituanismen an. B. Walczak (1999: 57) schreibt ebenfalls nichts über Lituanismen unter den ältesten Entlehnungen in der polnischen Sprache, woran sich aus der Sicht dieses Autors in der altpolnischen (ebd., 100f.), mittelpolnischen (ebd., 158), und neupolnischen Epoche (ebd., 247f.) nichts ändert. M. Witaszek-Samborska (1992: 51f.) behauptet, dass das Polnische aus manchen europäischen Sprachen nur wenige Lexeme übernommen 
hat, die im heute aktiven Wortschatz präsent sind. Einzelne Lehnwörter stammen u.a. aus dem Litauischen, z.B. znicz (Grablicht). Den Einfluss dieser Sprachen (wie u.a. des Litauischen) auf das Polnische hält die Autorin für gering, und deren Lehnwörter sind in der polnischen Lexik nur peripher.

An dieser Stelle ist festzustellen, dass zwischen zwei Varianten der polnischen Sprache unterschieden werden muss, der allgemeinpolnischen Sprache (Schriftsprache) und der Polnischen Sprache im Grenzgebiet (vgl. Karaś 1999: 55). Es gibt jedoch eine ganze Menge von Bezeichnungen für diese zweite Variante in der einschlägigen Literatur. Die Mannigfaltigkeit der Termini zur Bezeichnung des Polnischen im Grenzgebiet dokumentiert K. Węgorowska (2004: 95), und K. Handke (1997: 9ff.) beschäftigt sich mit dem Problem des Polnischen im nördlichen Grenzgebiet vor dem Hintergrund der territorialen und sozialen Unterschiedlichkeit der polnischen Sprache. Diese Diversität der Termini und das Problem ihrer Verwendung sind nicht Gegenstand dieser Arbeit.

Zuerst soll im Folgenden der fremde Einfluss auf die polnische Schriftsprache ausgearbeitet werden. Z. Kurzowa (1993b: 60) konstatiert, dass die Grenzdialekte in den verschiedenen Zeitperioden umfangreiches Lehngut aus dem russischen (ukrainischen und weißrussischen) Wortschatz in die polnische Schriftsprache vermittelt haben, darunter auch eine große Anzahl an Entlehnungen aus der litauischen Sprache. H. Karaś (1999: 45) hat die Standardvariante der polnischen Sprache bei Schülern polnischer Oberschulen in Litauen untersucht. Zum Wortschatz bemerkt die Autorin die Anwesenheit von vielen Regionalismen und Grenzdialektismen. Die Mehrheit bilden alte Weißruthenismen oder Russizismen, seltener alte Lituanismen. Neuere Entlehnungen aus dem Litauischen treten auch nur sporadisch auf. Oft sind es semantische Lehnübersetzungen aus dem Russischen oder Weißrussischen. Seltener kommen Wortbildungslehnübersetzungen aus dem Russischen, vereinzelt aus dem Litauischen vor.

Z. Kurzowa (1982: 14) unterscheidet im Polnischen des Grenzgebiets zwei chronologisch und sozial verschiedene Varianten. Die erste ist die Schriftsprache der gebildeten Bevölkerung. Sie wird durch gewisse Archaismen gekennzeichnet und hat alte historische Wurzeln, die bis in die ersten polnisch-litauischen Kontakte zurückreichen. Die zweite Variante, viel neuer und ohne Archaismen, sind Volksdialekte des sich erst in der 2. Hälfte des 19. Jahrhunderts polonisierenden weißrussischen und litauischen Bauerntums. 
Der Einfluss des Litauischen auf die polnische Schriftsprache war geringer als auf ihre Variante im Grenzgebiet. J. Rieger (1996: 16) jedoch schreibt, dass die polnische Sprache der Schriftsteller, die mit dem östlichen Grenzgebiet Polens verbunden waren, schon seit dem 16. Jahrhundert eine große Rolle spielte, um im 19. Jahrhundert wesentlich die polnische Schriftsprache zu beeinflussen. Das wird z.B. an der Sprache von zwei der bedeutendsten polnischen Schriftstellern sichtbar - Mickiewicz und Słowacki.

M. T. Lizisowa (1983) hat die Quellen der regionalen Lexik des III. Status des Großfürstentums Litauen bestimmt. Sie stellt fest, dass es in der polnischen Übersetzung dieser Urkunde nur wenige litauische Entlehnungen gibt (M. T. Lizisowa 1983: 106).

K. Nitsch (2006: 32f.) schrieb im Jahre 1925 über die polnische Sprache bei Wilna, dass sie in Bezug auf das grammatische System und den Wortbestand ganz neu ist (sie entstand in der 2. Hälfte des 19. Jahrhunderts (Jakubowski 2006: 40-41). Sie enthält viele lebendige weißrussische Elemente und eine erheblich kleinere Zahl nicht mehr gebräuchlicher litauischer Wörter. Gemäß Jakubowski trifft man hierin eine gewisse Anzahl litauischer Wörter. Sie entstammen dem materiellen und wirtschaftlichen Bereich, und es handelt sich dabei überwiegend um Begriffe, die nicht täglich benutzt wurden. Sie zeugen vom Litauentum der ehemaligen Bewohner dieser Gegend.

Derselben Meinung ist H. Turska (1983: 16). Die polnische Sprache bei Wilna charakterisiert sich dadurch, dass sie viele Eigenschaften der litauischen und weißrussischen Sprache bewahrt hat. Litauische Elemente treten aber relativ selten auf.

I. Maryniakowa/I. Grek-Pabisowa (1994: 96) haben die polnischen Dialekte bei Wilna untersucht. Sie haben festgestellt, dass in einem der Dörfer am Fluss Wilia (Bujwidze) die Bewohner nur einzelne Wörter aus dem Litauischen kennen. Die Jüngeren können ein bisschen Litauisch aus der Schule in Wilna.

T. Graczykowska (1999: 379) hat den litauischen Wortschatz im Wochenblatt Chata Rodzinna („Die Familienhütte”) aus Kaunas untersucht. Diese Zeitschrift erschien in den Jahren 1923-1940. Die Autorin hat in ihrer Arbeit nur den lokalspezifischen Wortschatz berücksichtigt. Das gesammelte Wortgut ist sehr differenziert. Teils sind es Lexeme, die früher im Polnischen des Grenzgebiets registriert wurden und teils solche, die sich wegen der vorherrschenden politischen Situation in Litauen in der Zwischenkriegszeit ent- 
wickelt haben (es sind u.a. Namen politischer Gruppierungen, Organisationen). Die Liste der Lituanismen ist nicht lang. Die Autorin hat gerade einmal 32 Wörter ermittelt, die meistens nur einige wenige Male auftreten. Für eine derartig weite Zeitspanne ist nach T. Graczykowska der Anteil der litauischen Wörterbuchbesonderheiten gering. Die Autorin ordnet ihr Material in drei Gruppen: Lituanismen, Zitate und geographische Namen.

H. Karaś (2001a: 212f.) unterscheidet im Polnischen des Gebiets Kaunas zwei Arten der Lexik: den Wortschatz der breiteren und engeren Reichweite. Die polnische Sprache bei Kaunas ist eine lokale Variante des Polnischen der Nordgrenze, die viele lexikalische Merkmale aufweist, die auch anderen polnischen Dialekten in Litauen, Lettland und Weißrussland gemein sind. Die Lexik von der engeren Reichweite, die in der Regel auf die Gebiete bei Kauen beschränkt ist, hebt sich von der polnischen Sprache bei Wilna u.a. durch eine größere Anzahl von Lituanismen ab, die in den Dialekten bei Wilna entweder nicht bekannt oder seltener zu finden sind (vgl. auch Karaś 2001b: 143).

Die oben angeführten theoretischen Ausführungen bestätigen die Tatsache, dass Lituanismen in der polnischen Sprache, sowohl in der Schriftsprache als auch in ihrer Grenzvariante, nur gelegentlich auftreten. Im Folgenden wird der Versuch unternommen, die Ursachen für diesen Befund zu bestimmen. Man nimmt an, dass zu den Hauptgründen das niedrige Prestige der litauischen Kultur und die Tatsache, dass Litauisch in der Zeit des Großfürstentums Litauen nicht die Amtssprache war, gehören.

Das mit Polen verbundene Großfürstentum Litauen war ethnisch nicht einheitlich. Es war der litauisch-ruthenische (weißrussich-ukrainische) Staat, und diese Tatsache war von großer Bedeutung für Litauen selbst, aber auch für die Entwicklung der polnischen Kultur und Sprache auf dem Gebiet des Großfürstentums (Kurzowa 1993b: 15). Vom 13. bis zum 14. Jahrhundert erfolgte die sprachliche und nationale Ruthenisierung der höheren Sozialschicht Litauens. Im litauischen Staat begann die ruthenische (stärker weißrussisch als ukrainisch geprägte) Sprache zu herrschen, nicht nur als eine Amts- und offizielle Sprache, sondern auch als die Familiensprache. Bei dieser Koexistenz von zwei Nationen erwiesen sich die Litauer als ethnisch schwächer. Die Ortsansässigen gaben der allmählichen Ruthenisierung nach (Kurzowa 1993b: 17).

Was die Kontakte Litauens mit Polen anbetrifft, schreibt Z. Kurzowa (1993b: 19), dass nicht die Anzahl der polnischen Siedler über die Verbrei- 
tung des Polentums im Großfürstentum Litauen entschieden hat, sondern die Kraft und Attraktivität der polnischen Kultur und Zivilisation. Auch M. B. Topolska (1984: 23) vertritt den Standpunkt, dass seit dem 16. Jahrhundert auf das Gebiet des Großfürstentums Litauen die attraktiven Inhalte des Humanismus und der Reformation aus dem Westen gelangten. Die Autorin setzt fort (ebd., 28), dass die polnische Sprache im 16. Jahrhundert durch die litauische und weißrussische Herrscherklasse verwendet wurde, als Ausdruck von ihren aktuellen kulturellen Ambitionen. Das Polnische eröffnete auch die größten Möglichkeiten, den multinationalen Staat, das Großfürstentum Litauen, zu integrieren.

Vom 16. bis zum 18. Jahrhundert erfolgte die sprachliche und nationale Polonisierung der litauisch-russischen höheren Schichten des Großfürstentums (Kurzowa 1993b: 19f.). So erstreckte sich im 18. Jahrhundert auf dem ganzen Gebiet der Krone und des Großfürstentums Litauen die polnische Sprache. Im 19. Jahrhundert erfolgte dann die sprachliche und nationale Polonisierung des litauischen und weißrussischen Bauerntums (ebd., 22).

Z. Kurzowa (1993b: 27) schreibt über die Eigenart des litauisch-polnischen Kontakts. Sie vermutet, dass die polnische Sprache in direkten Kontakt mit dem Weißrussischen und nicht mit dem Litauischen trat. Der eventuelle Einfluss des Litauischen auf das Polnische konnte nur durch die Vermittlung des Weißrussischen erfolgen. Über die Geschichte der polnischen Sprache im Nordgrenzgebiet schreibt auch I. Grek-Pabisowa (1997: 30f.).

K. Nitsch (2006: 34) konstatiert, dass es bei dem Austausch einer Sprache gegen eine andere nicht um ihre besonderen Werte ging, sondern ausschlieBlich um ihre praktischen Vorzüglichkeiten. Viel günstiger als Litauisch war eine slawische Sprache, nämlich Weißrussisch, weil es am leichtesten zu erlernen war und man konnte es sowohl im polnischen Gutshof als auch im russischen Amt benutzen.

Z. Kurzowa (1993a: 35) findet Litauisch fremd, unverständlich und für Slawen schwierig zu erlernen.

Z. Kurzowa (1993a: 317) behauptet, dass das Polnische immer schon die höheren Sozialschichten und Staatsinstitutionen repräsentierte. Bis heute sind die mehrsprachigen Bewohner aus den Nordgrenzgebieten der Ansicht, dass Polnisch schöner und sensibler ist als Weißrussisch und Litauisch. Das Polnische wird zur Verschönerung der Sprache und allgemein zum eleganteren Verhalten verwendet. 
A. Zielińska (1999: 13) konstatiert, dass polnisch zu sprechen das Attribut des Adelstandes war. Diese Tatsache entschied über die Attraktivität des Polnischen und sein hohes Prestige. Als die Autorin im Jahre 1994 die Untersuchungen bei Kaunas durchführte, schlussfolgerte sie, dass nur noch wenige Polen in ihren Familien die Tradition, polnisch zu sprechen, pflegen. Polnisch, das keine sozial-ökonomische Bedeutung mehr hat, ist für die Polen aber immer noch eine Sprache von höherem kulturellen Prestige als Litauisch. Sie empfinden oft eine Abneigung gegen das Litauische und beherrschen es lediglich zu einem geringen Grade (ebd., 14).

Die nächste Ursache ist die Gegebenheit, dass nach dem Krieg die Polen in Litauen bei Wilna dank der dichten Besiedlung ihre soziale, nationale und sprachliche Bindung bewahrt haben. Obwohl die polnische Sprache in Ämtern und im gesellschaftlichen Leben abgeschafft wurde, blieb sie jedoch Familiensprache. Zu ihrer Bewahrung trug auch die Kirche bei (Kurzowa 1993a: 314). In der Nachkriegszeit verlor die Vermittlung des Weißrussischen ihre Bedeutung. Dennoch übte das Litauische keinen Einfluss auf die polnische Sprache aus, weil eine solche Entwicklung die russische Sprache verhinderte (Kurzowa 1993a: 322).

I. Maryniakowa / I. Grek-Pabisowa (1994: 98) schreiben, dass die Ortschaften, in denen sie Dialekte untersuchten, früher kleine Städte waren, die vor allem von Polen bewohnt wurden. Der Verlust des Status der Kleinstadt seine Umwandlung in dörfliche Siedlungen - hemmte den Zufluss einer fremdsprachigen, russischen und litauischen Administration. So wurde in einem gewissen Maße die Russifizierung und Lituanisierung der polnischen Sprache eingeschränkt ${ }^{1}$.

Zusammenfassend lässt sich feststellen, dass die Gründe der geringen Präsenz der Wörter litauischer Herkunft im Polnischen geschichtlich-geografischer, praktischer, kulturell-ästhetischer und administrativer Natur sind.

\section{Abkürzungen}

fig. - figürlich

lit. - litauisch

weißruss. - weißrussisch

1 Wir verweisen auf die weitere Literatur in den Arbeiten von Rembiszewska (2006) und (2007). 


\section{Literatur}

BAŃKowsKi A., 2000, Etymologiczny stownik języka polskiego, Bd. 1-2 A-K, L-P, Warszawa: Wydawnictwo Naukowe PWN.

Boryś W., 2005, Stownik etymologiczny języka polskiego, Kraków: Wydawnictwo Literackie.

BRÜCKNer A., 1927, Słownik etymologiczny języka polskiego, Kraków: nakładem Krakowskiej Spółki Wydawniczej.

Dıugosz-Kurczabowa K., 2005, Stownik etymologiczny języka polskiego, Warszawa: Wydawnictwo Naukowe PWN.

GraczYKowSKA T., 1999, Lituanizmy leksykalne w kowieńskim tygodniku „Chata Rodzinna", in: J. Rieger (Hg.), Język polski dawnych Kresów Wschodnich. Bd. 2. Studia i materialy, Warszawa: Wydawnictwo Naukowe „Semper”, S. 377-384.

Grek-Pabisowa I., Maryniakowa I., 1997, Język polski na Kresach północno-wschodnich dawniej i dziś, in: I. Grek-Pabisowa (Hg.), Historia i współczesność języka polskiego na Kresach Wschodnich, Warszawa: Polska Akademia Nauk. Instytut Slawistyki, S. 27-109.

HandKe K., 1997, Polszczyzna północnokresowa na tle terytorialnego i społecznego zróżnicowania języka polskiego, in: I. Grek-Pabisowa (Hg.), Historia i wspótczesność języka polskiego na Kresach Wschodnich, Warszawa: Polska Akademia Nauk. Instytut Slawistyki, S. 9-26.

JAkUBowski J., 2006, Język polski w Kowieńszczyźnie (Przeglad Współczesny IX, t. XXXII, styczeń-marzec 1930, s. 450-456), in: J. Rieger (Hg.), Język polski dawnych Kresów Wschodnich, Bd. 3, Warszawa: Wydawnictwo Naukowe „Semper", S. 37-41.

Karaś H., 1999, Uwagi o języku uczniów polskojęzycznych szkół średnich na Litwie, in: J. Rieger (Hg.), Język polski dawnych Kresów Wschodnich, Bd. 2. Studia i materiaty, Warszawa: Wydawnictwo Naukowe „Semper”, S. 47-55.

Karaś H. (Hg.), 2001a, Język polski na Kowieńszczyźnie. Historia. Sytuacja socjolingwistyczna. Cechy językowe. Teksty, Warszawa: Dom Wydawniczy ELIPSA.

KARAŚ H., 2001b, O specyfice polszczyzny kowieńskiej (w porównaniu z odmianą wileńsko-smołwieńską), in: J. Rieger (Hg.), Studia nad polszczyzna kresowa, Bd. 10, Warszawa: Wydawnictwo Naukowe „Semper”, S. 137-160.

Karaś M. (Hg.), 1974, Aleksander Brückner. Poczqtki i rozwój języka polskiego. Wybór prac pod redakcja Mieczystawa Karasia, Warszawa: Państwowe Wydawnictwo Naukowe.

Klemensiewicz Z., 1965, Historia języka polskiego. Część II. Doba średniopolska (od poczatków XVI wieku do ósmego dziesięciolecia XVIII wieku), Warszawa: Państwowe Wydawnictwo Naukowe. 
Klemensiewicz Z., 1972, Historia języka polskiego. Część III. Doba nowopolska (od ósmego dziesięciolecia XVIII wieku do r. 1939), Warszawa: Państwowe Wydawnictwo Naukowe.

Kurzowa Z., 1982, Język polski na Kresach północno-wschodnich, in: J. Rieger, W. Werenicz (Hg.), Studia nad polszczyzna kresowa, Bd. 1, Wrocław-Warszawa-Kraków-Gdańsk-Łódź: Zakład Narodowy im. Ossolińskich, Wydawnictwo Polskiej Akademii Nauk, S. 13-17.

Kurzowa Z., 1993a, Język polski Wileńszczyzny i kresów północno-wschodnich XVI$-X X$ w., Warszawa-Kraków: Wydawnictwo Naukowe PWN.

Kurzowa Z., 1993b, O mowie Polaków na kresach wschodnich, Kraków: Wydawnictwo i Drukarnia ,Secesja”.

Lizisowa M. T., 1983, Źródła regionalnego słownictwa III Statutu Wielkiego Księstwa Litewskiego, in: J. Rieger, W. Werenicz (Hg.), Studia nad polszczyzna kresowq, Bd. 2, Wrocław-Warszawa-Kraków-Gdańsk-Łódź: Zakład Narodowy im. Ossolińskich, Wydawnictwo Polskiej Akademii Nauk, S. 103-118.

Maryniakowa I., Grek-Pabisowa I., 1994, Z najnowszych badań terenowych na Wileńszczyźnie, in: J. Rieger (Hg.), Studia nad polszczyzna kresowa, Bd. 7, Wrocław-Warszawa-Kraków: Zakład Narodowy im. Ossolińskich, Wydawnictwo Polskiej Akademii Nauk, S. 95-99.

Nitsch K., 2006, Język polski w Wileńszczyźnie (Przeglad Współczesny XII, styczeń 1925, s. 25-32), in: J. Rieger (Hg.), Język polski dawnych Kresów Wschodnich. Bd. 3, Warszawa: Wydawnictwo Naukowe „Semper”, S. 29-35.

Rembiszewska D. K., 2006, Wpływy bałtyckie w „Słowniku dialektu knyszyńskiego" Czesława Kudzinowskiego, Acta Baltico-Slavica 30, S. 373-389.

RemBiszewsKa D. K., 2007, O przypuszczalnych wpływach litewskich w Słowniku dialektu knyszyńskiego Czesława Kudzinowskiego, Acta Baltico-Slavica 31, S. 213-234.

Rieger J., 1996, Co wiemy o języku polskim na Kresach Wschodnich?, in: J. Rieger (Hg.), Język polski dawnych Kresów Wschodnich, Bd. 1. Studia i materiaty, Warszawa: Wydawnictwo Naukowe „Semper”, S. 11-16.

SŁAwski F., 1958-1965, Słownik etymologiczny języka polskiego, Bd. 2 K-Kot, Kraków: Towarzystwo Miłośników Języka Polskiego.

SŁAwSKi F., 1970-1974, Słownik etymologiczny języka polskiego, Bd. 4 La-Łapucha, Kraków: Towarzystwo Miłośników Języka Polskiego.

SŁoński S., 1953, Historia języka polskiego w zarysie, Warszawa: Państwowe Wydawnictwo Naukowe.

Sobol E. (Hg.), 1999, Słownik wyrazów obcych, Warszawa: Wydawnictwo Naukowe PWN.

Topolska M. B., 1984, Czytelnik i ksiażka w Wielkim Księstwie Litewskim w dobie Renesansu i Baroku, Wrocław: Zakład Narodowy im. Ossolińskich - Wydawnictwo. 
Turska H., 1983, Język polski na Wileńszczyźnie, in: J. Rieger, W. Werenicz (Hg.), Studia nad polszczyzna kresowa, Bd. 2, Wrocław-Warszawa-Kraków-Gdańsk-Łódź: Zakład Narodowy im. Ossolińskich, Wydawnictwo Polskiej Akademii Nauk, S. 15-23.

Walczak B., 1999, Zarys dziejów języka polskiego, Wrocław: Wydawnictwo Uniwersytetu Wrocławskiego.

WęGOROwsKa K., 2004, Językowe świadectwa kultury i obyczajowości Kresów Pótnocno-Wschodnich. Utrwalone we wspomnieniach ich bytych mieszkańców, Zielona Góra: Oficyna Wydawnicza Uniwersytetu Zielonogórskiego.

Witaszek-Samborska M., 1992, Wyrazy obcego pochodzenia we współczesnej polszczyźnie. Na podstawie słowników frekwencyjnych, Poznań: Wydawnictwo Nakom.

Zielińska A., 1999, O polszczyźnie na Litwie Kowieńskiej, in: J. Rieger (Hg.), Studia nad polszczyzna kresowa, Bd. 9, Warszawa: Wydawnictwo Naukowe „Semper", S. 11-32.

\section{Lithuanian loanwords in selected Polish language dictionaries}

( s u m m a r y)

This paper examines the frequency of words of Lithuanian origin in selected, recently published, Polish language dictionaries. The conducted research shows that the frequency of such words is low. There are only three Lithuanisms in the Stownik etymologiczny języka polskiego by W. Boryś and in the Słownik etymologiczny języka polskiego by K. Długosz-Kurczabowa there are none. The low frequency of these words is discussed in many scholarly works, both those on Polish literary language and those on the Polish language in the Kresy area (the eastern borderlands). This paper tries to establish the reasons behind this situation. The reasons are, as the subject literature shows, historical, geographical, practical, aesthetic, cultural and administrative in nature. 